\title{
NOTA
}

\section{HACIA UNA EXPLICACIÓN SOCIOLINGÜÍSTICA DE LA EXTENSIÓN DEL ARTÍCULO EN ESPAÑOL MEDIEVAL}

\author{
JESÚs Llopis GANGA \\ (Universidad de Alicante)
}

Uno de los hechos que quizás más nos llaman la atención al leer textos de los siglos XII-XIII y comparar sus frases nominales con las del español de hoy es que el español ha sufrido un cambio lingüístico que, de modo global, se puede caracterizar como una extensión en el empleo del artículo determinado, pues bien, en este trabajo intentaremos aproximarnos a una explicación sociolingüistica ${ }^{1}$ de este cambio lingüístico.

Hasta hace poco tiempo la Historia de la Lengua había estado dominada por una visión formalista centrada exclusivamente en los factores de espacio y tiempo, por lo que excluían así el factor social de la lengua explicando la evolución de la lengua únicamente atendiendo a aspectos formales, exclusivamente lingüísticos e internos. Saussure ${ }^{2}$, el primero en plantear la autonomía lingüística, dejó fuera de la lengua todo lo que pertenecía al hablante, ciñéndo, de este modo, la lingüística exclusivamente a los factores internos de la lengua (factores internos vs. factores externos). A partir de entonces se realizaron estudios fundamentalmente formalistas e inmanentistas, pero con el paso del tiempo fue haciéndose evidente que no se podía hablar de la lengua sin hablar de los hablantes, pues ésta se encuentra sujeta a ellos.

De este modo, desde los últimos eslabones del planteamiento estructuralista del cambio lingüístico, surgieron las primeras propuestas de incorporación de lo

1 La concepción sociolingüística de la Historia de la Lengua que adoptamos en nuestro trabajo se enmarcaría dentro del modelo y de las propuestas metodológicas que defiende Juan Luis Jiménez Ruiz en «Fundamentos epistémicos para una concepción sociolingüística de la Historia de la Lengua», Lexis, Vol. XVIII, 2, 1994, págs.211-225.

2 F.De Saussure, Curso de lingüística General, Alianza, Madrid, 1987, pág. 47. 
social a la lingüística. Así, Malmberg ${ }^{3}$ defiende que la evolución de la lengua no era más que un aspecto particular de la evolución social y cultural, por lo que las causas últimas de los cambios residen para él en las fuerzas que dirigen la evolución social y cultural en general. Coseriu ${ }^{4}$ considera que lo interno de la lengua no puede ser sólo la lengua porque también está inmerso en ella el hablante, reconociendo, por consiguiente, que el cambio está producido por presiones de la misma lengua y por factores sociales.

Ahora cada vez con más frecuencia se viene asumiendo que la explicación de 1 a evolución de las lenguas desde un punto de vista exclusivamente lingüístico resulta insuficiente. Esto ha provocado una renovación lingüística que, apoyándose en la contribución sociolingüística, pretende superar la propia limitación interna de la explicación funcionalista de la evolución de las lenguas.

Parece natural que la sociolingüística pueda hacer aportes valiosos en este campo ya que es la disciplina que ha desarrollado las herramientas metodológicas necesarias para analizar la lengua como plurisistemática. Para Silva-Corvalán ${ }^{5}$, en oposición al concepto estructuralista de lengua como sistema monolítico, uniforme y homogéneo, la sociolingüistica propone el concepto de sistema inherente y ordenadamente heterogéneo y variable. Creemos que esta heterogeneidad coexistente en un sistema sincrónico dado explicaría deuna manera más adecuada el paso de un estado de lengua a otro, es decir, la diacronía.

Probablemente este desapego de los factores sociales estuvo motivado por las circunstancias historico-lingüísticas del momento. Romaine ${ }^{6}$ observa que los lingüistas nunca han ignorado la variación, sino que ha sido simplemente más conveniente asumir como un principio pragmático que las lenguas y las comunidades lingüísticas son homogéneas. Esta asunción de homogeneidad ha sido en gran medida la que ha permitido el planteamiento de una base descriptiva lingüística sólida que ha hecho posible el desarrollo de la sociolingüística.

A diferencia del modelo estructural, que pone énfasis en los factores internos, uno de los principios básicos de la sociolingüística histórica es que no es posible comprender el desarrollo de un cambio lingüístico fuera de la estructura social de la comunidad en la que ocurre. El estructuralista se refiere a las presiones del sistema, el sociolingüística, por contra, se refiere a las presiones sociales que continuamente operan sobre la lengua. La investigación sociolingüísta ha

3 B. Malmberg, «Linguistique ibérique et ibéro-romane. Problèmes et méthodes», Studia Linguistica, 15, págs. 57-113.

4 E.Coseriu, Sincronía, diacronía e historia. El problema del cambio lingüístico, madrid, Gredos, 1973, págs. 11-28. 155 .

S C.Silva-Corvalán, Sociolingüística. Teoría y análisis, Alhambra, Madrid, 1989, págs. 154-

6. Somaine, Sociohistorical linguistics, Cambridge, Cambridge University Press, 1982. 
comprobado el hecho de que ciertas diferencias en el habla de los miembros de una comunidad covarían con ciertos factores sociales; por lo tanto, muchos de estos cambios tienen una motivación social. Para la sociolingüística está claro que el estudio del cambio lingüístico debe hacerse tomando en cuenta el contexto social ya que la variación social desempeña un papel importante en el cambio.

Debemos buscar una vía que adopte criterios más amplios y abarcadores que consideren la compleja realidad del proceso histórico de la evolución sociolingüística ${ }^{7}$. Creemos conveniente incorporar el elemento humano (los hablantes) en la Historia de la Lengua, y esto sólo sería posible mediante la transformación de los modelos lingüísticos en modelos sociolingüísticos ${ }^{8}$, es decir, los cambios en la lengua están íntimamente relacionados con transformaciones en la estructura social y cultural de esa comunidad. Así, la Historia de la Lengua deberá recoger una nueva coordenada que nos permita situar las relaciones sitemáticas entre los datos lingüísticos y los factores sociales y situacionales.

El análisis lingüístico del uso de la lengua en su contexto deja traslucir un mundo surgido de la interacción social ${ }^{9}$. Todo esto nos acerca a una Historia sociolingüística de la lengu $a^{10}$ que, «como superadora de la dialéctica que enfrenta el cientificismo imperante en el dominio lingüístico con el carácter humano de la lingüística desde un punto de vista social, aglutina el objetivismo del cientificismo con el humanismo de la recuperación de los valores del hablante $\gg^{11}$.

Teniendo en cuenta esto, es evidente que hay fenómenos lingüísticos -como el que estudiamos en este trabajo: la extensión del artículo en el siglo XIII- que se comprenden mucho mejor en el contexto de concepciones «conflictivistas» ${ }^{12}$, según las cuales «las lenguas se definen como síntomas de comportamientos sociales». Así concebida, la lengua es una estructura movida por los intereses y la libertad de los hablantes que producen el cambio lingüístico.

Los textos medievales son muy generosos en cuanto a que en ellos es posible hallar la evidencia "práctica» de este cambio cuantitativo en el empleo del

7 F. Gimeno, «Hacia una sociolingüística histórica» Estudios de Lingüística, 1, (1983), pág. 182.

8 J.A. Villena Ponsoda, Fundamentos del pensamiento social del lenguaje, Agora, Máaga, 1992, pág. 29.

9 R. Anttilla, «Linguistics and Philology» apud R. Bartsch (ed), Linguistics and neighboring disciplines, North Holland Publ., 1975, págs. 145-155. Uriz Pemán, M., «Reflexiones críticas sobre la influencia de los factores sociales en el individuo», Letras de Deusto, № 57, 1993, pág. 57.

10 A. Várvaro, «Storia della Lingua: passato e prospettive di una categoria controversa», apidd La parola nel tempo, II Mulino, Bolonia, 1984, págs. 9-77.

Mondéjar, J., «Lingüística e historia», Revista española de Lingüística, 10, I, 1980, págs. i-48.

"I.L. Jiménez Ruiz, Op. cit., págs. 215-216.

12 F. Abad, «Ejemplos y muestras del método en Historia de la Lengua Española», Antiqua et nova Romania. Estudios lingüísticos y filológicos en honor de J. Mondéjar, Universidad de Granada, 1993, págs. 4-5. 
artículo. Citaremos algunos ejemplo que constaten nuestra afirmación. Advertimos de ar temano la insuficiencia del análisis que hemos realizado de los textos de la época. Con estos ejemplos no queremos demostrar de forma empírica la veracidad de nuestro planteamiento, sino que únicamente pretendemos justificar nuestra propuesta. No perseguimos que ésta sea verdadera, sino únicamente que sea correcta. Reemplazamos un análisis más amplio y exhaustivo de los textos de esta época para otro momento más idóneo, debido a la tamaña embergadura de esta empresa.

1. Señora madre vieja la mi plazentería (Buen Amor, 813)

2. Sennor, los tus amigos en el mar fallan credos (Milagros de Nuestra Señora, 456c) 717)

3. Las oraciones tuyas son de Dios exaudidas ( Santo Domingo de Silos,

4. Retrayen los sos fechos, los sos laudes cantavan (Milagros de Nuestrá Señora, 496c)

5. No osó traspassar del Rey el su mandado (Santo Domingo, 744b)

6. Con gente de mi casa é con los del Andalucía entiendo de estar presto (Crónica de Juan II, s 301b)

7. Que digas el tu nombre al rey mio senyor (Libro de Apolonio, 171)

8. El vuestro gran servicio no se faría de tan buen corazón como el mio pequeño (Amadís de Gaula, 162) 2780)

9. Ya primos, los mis primos, don Elvira e doña Sol (Poema de Mio Cid, 500)

10. Que en pleye la lengua et al espada meta mano (Poema de Mio Cid,

11. Contol el yelmo, que lego a la carne (Poema de Mio Cid, 500)

12. Ellos veyen la riqueza que el moro sacó ( Poema de Mio Cid, 2659) 1019)

13. Aduzen les los comeres, delent ge los parecen (Poema de Mio Cid, 152d)

14. E los mas volen recabdar la cosa más querida (Libro de Buen Amor, 2896)

15. Teniendo yvan armas, entraron se a la cibdad (Poema de Mio Cid,

16. Miran Valençia commo iaze la cibdad (Poema de Mio Cid, 1613)

Pero la extensión del uso del artículo se verá más claro contrastando textos de distintos periodos. Proponemos como primer ejemplo un documento castellano del año 1196 «Barruelo de Santmillán: carta de arras y venta de unas heredades», recogido en la Crestomatía ${ }^{13}$ de Pidal:

Ego Monro Roizi do la eredad que et en Bariolo et en Ribiella: et en Sancte Fagund' et en Barrio questo heo i, en mont et en font, et quanto comparo et ganaro et en mios dias et sos; et dujo por suas harras a mia mulier Mejor Garciaz. Et dojo la heredad que he en Ponguera, en pennos, quanto eo

:3 R. Menéndez Pidal, Crestomatía del español medieval, Gredos, Madrid, 1971, pág. 56. 
i et ganaro, por sos bestidos, nobrada mientre quinientos soldos.

Consideramos como segundo ejemplo el «Prólogo» de Las siete Particias (1256-65), también recogido en la Crestomatía de Pidal:

Porque las voluntades et los entendimientos delos omnes son departides en muchas maneras, por ende los fechos et las obras dellos no acuerdar en uno. E desto nascen grandes contiendas et muchos otros males por las tierras; por que conviene a los Reyes, que an a tener et a guardar sus pueblos en paz et en iusticia, que fagan leyes et posturas et fueros por que el desacuerdo que han los omnes naturalmientre entressi se acurde por fuerça de derecho assí que los buenos viven bien et en paz et los malos sean escarmentadios de sus maldades.

Como podemos observar a simple vista, el primer texto, que pertenece al siglo XII, presenta una menor frecuencia en el uso del artículo o de actualizadores que el segundo, perteneciente al siglo XIII.

En el primer texto aparecen varios sustantivos «concretos» o particulares con ausencia de artículos (en mont et en font). Esto nos puede resultar raro y paradójico hoy en día, pues si es un sustantivo concreto, lo usual para nosotros sería que fuera actualizado. Además, cuando aparece el artículo detcrminado on estos textos (la heredad), y a no funciona tanto en el discurso por los interlocutores.

En el segundo texto nos encontramos con un uso mayor del artículo determinado, pues ya en él todos los sustantivos concretos van precedidos del artículo (las obras, las tierras, los Reyes, etc.), y también algunos sustantivos abstractos precedidos de artículo (las voluntades, los entendimientos), mientras que otros sustantivos abstractos presentan ausencia de artículo (en paz et en iustiçia, por fuerça) Sin embargo, estos últimos sustantivos también hoy podrían aparccer sin artículo por su carácter de expresiones fijas o fosilizadas.

Por lo tanto, nos parece observar que a partir del siglo XIII todos los sustantivos concretos que hasta entonces vacilaban en la presencia de artículo van a exigir su presencia, y su uso se extenderá incluso a muchos sustantivos abstractos.

Una clase léxica de sustantivos - los concretos, tangibles o claramente delimitados - muestran a partir del siglo XIII en adelante un comportamiento diacrónico muy estable, en el sentido de que desde los primeros textos analizados de este siglo deben llevar artículo u otro modificador y no pueden por sí solos aparecer como constituyentes de oración. Puede inferirse, entonces, que el español introdujo la categoría «artículo» inicialmente en este tipo de sustantivos, porque su naturaleza semántica - ser concretos y con límites-era acorde con uno de los valores del artículo, el de dar referencia, concretar y aproximar entidades.

Otros sustantivos - los abstractos - admiten, en cambio, en el español medieval la ausencia de este clítico nominal, y sólo ellos experimentaron 
durante el periodo estudiado un cambio gradual consistente en la introducción del artículo.

Concepción Company ${ }^{14}$ afirma que allí donde es viable confrontar distintos manuscritos de una misma obra, se puede observar que. efectivamente los diferentes copistas eran sensibles a la presencia o no del artículo, e introdujeron el artículo en el sustantivo que carecía de él. Nos parece evidente que la sensibilización ante una forma lingüística es señal inequívoca de que esas formas habían experimentado un cambio o estaban cambiando en la época del copiado del texto en cuestión.

Podemos observar esta sensibilización ante la extensión del uso del artículo en las ediciones crípticas de muchas obras medievales de una forma bastante generosa. Por ejemplo, en la estrofa 77 verso c el editor ${ }^{15}$, en su edición crítica, introduce la siguiente nota:

\section{$77 \mathrm{c}$ I falta la}

$77 \mathrm{c}$ el abbat de la casa dio'l la sacristanía.

Pretende así señalar que en el manuscrito $I$, que es el que toma como base para su edición, no aparece el artículo la. El editor introduce el artículo la pero en cursiva, indicando de este modo que se trata de una corrección procedente del manuscrito $F$, texto que el editor ha tenido en cuenta para, en momentos apropiados, corregir las lecturas difíciles, estropeadas o las que no tienen sentido.

Casos como éste son muy abundantes en cualquier edición crítica de calidad de textos medievales; citamos a continuación algunos cuantos ejemplos, aunque no es nuestro interés, en este trabajo, hacer un análisis exhaustivo de ello.

De la Vida de Santo Domingo de Silos ${ }^{16}$.

27 b) que de la leÿ vieja fueron contenedores.

27 b) P- $/ \mathrm{Aa}$

42 a) $E l$ obispo de la tierra oyó del buen cristiano.

42 a) H-E el.

$60 \mathrm{~b})$ qui por salvar las almas dexaron los poblados.

60 b) E - [los $]$

Del Poema del Mio Cid ${ }^{17}$ :

14 C. Company, «Extensión del artículo en español medival», Romance Philology, 44/4, 1991, págs. 402-424. 1989

is M. Genli, Ediciónde Milagros de Nuestra Señora de Gonzalo de Berceo, Cátedra, Madrid,

16 Gonzalo de Berceo, Vida de Santo Domingo de Silos, Edición de Teresa Labarta de Chaves, Editorial Castalia, Madrid, 1990.

17 Colin Smith, Edición del Poema del Mio Cid, Catedra, Madrid, 1989 
165 non les diesse mio Çid de la ganançia un dinero malo. $165 \mathrm{~B}$, L y MP suprimen el artículo y leen de ganançia.

Nos encontramos, pues, ante un lento y gradual cambio sintáctico en el comportamiento del artículo y del sustantivo. Lo más notable es que sólo cierto tipo de sustantivos -abstractos, de masa, de referencia única y genéricos (voluntad, agua, parayso, leones) - admite construcciones alternativas con presencia o ausencia de artículo en el español medieval. Quedan excluidos de este doble empleo los sustantivos concretos (tangibles, delimitables) en número singular (mesa, silla, sartén), ya que éstos aparecen con artículo, con otro determinante o con modificadores. Lo más relevante de este aspecto es que el comportamiento gramatical de una forma es sintomático de su valor scmántico.

En cuanto a las causas de este fenómeno, Company ${ }^{18}$ considera que se trata de un cambio en cuya motivación interactuaron dos factores:

a) El primero sería la existencia, debida a la indeterminación de ciertas voces en cuanto a la asignación de categoría léxica, de un tipo de sustantivos que funcionan como adjetivos: los sustantivos genéricos humanos como moros, castellanos, cristianos, españoles, sabios, infantes, maestros, ctc., pueden tener tanto carácter referencial como predicativo, es decir, pueden ser sustantivos y adjetivos.

En oraciones como vinieron moros o nacieron infantes caben las dos interpretaciones; en primer lugar como sujeto 'los moros vinicron', 'los infantes nacieron' y, en segundo lugar, como predicativo: 'vinieron moros [y después sc hicieron cristianos]', y 'nacieron infantes [y muricron siendo condes]'.

Esta autora considera que la presencia del artículo resolvió la ambigüedad potencial de éstos y les asignó pleno carácter referencial; esto es, marcó plenamente su valor sustantivo. El artículo scñaló formalmente un empleo referencial que antes sólo venía dado por el contexto. De esta forma nos encontraríamos ante un cambio analógico en el que el artículo amplió su aplicación como indicador de sustantivización motivado por una indeterminación categorial. Visto así, este valor del artículo que nos propone la autora estaría de acuerdo con los estudios más recientes sobre la función del artículo en cspañol. Según Alarcos ${ }^{19}$, la sustantivación es una de las funciones del artículo, éste transpone a función nominal los segmentos que originariamente desempeñan una función. Así pues, podemos decir que el artículo convierte al nombre común (o clasificador, como lo llama Alarcos, ya que clasifica diferencialmentc

\footnotetext{
18 C. Company, Op. Cit., págs. 416-419.

19 E. Alarcos Llorach, «El artículo en español», en To Honor R. Jakobson, I, The
} Hague, 1967, págs. 18-24. 
unas realidades respecto a otras) en nombre propio (o identificador, ya que iden:ifica sin posible ambigüedad, en una situación dada, una realidad determinada.

Esta circunstancia estaría en íntima relación con la distinción en las gramáticas de la categoría del sustantivo frente a la del adjetivo. Antes de la Edad Media susiantivos y adjelivos eran lo mismo, todavía no poseían una clara diferenciación er cuanto a la calegoría léxica. Prisciano todavía consideraba que el sustantivo expresaba «substantia cum qualitate» (luego, todavía no se había configurado lal distinción). Se diferenciaron en la Edad Media, pues entonces se consideró relevante diferenciar, ya en el ámbito propiamente lingüistico, entre la «substantia» y la «qualitatia»; esta distinción entre la sustancia (lo esencial) y la cualidad (lo accidental), motivada por la relevancia que esta diferenciación filosófica tuvo en la época, adquirió una focalización tan importante en la organización de los prismas ideológicos que consiguió su plasmación en la organización de los prismas lingüísticos: la di ferenciación entre las categorías verbales de sustantivo y adjetivo.

b) El scgundo factor es que en español los sustantivos genéricos sin artículo son candidatos ideales a ser no referenciales, indefinidos y de información nueva. Cuando estos sustantivos aparecen en función de sujeto rompen, en consecuencia, la expectativa del hablante u oyente de lo que debe ser un sujeto. Así, la introducción del artículo, según Company, resolvió, en gran medida, esta difieultad en la perspectiva funcional de la oración. Fue este tipo de sustantivos -abstractos-, el que propagó el uso del artículo cuando funcionaban como sujeto, porque el artículo asignó carácter referencial y definido a estos sustantivos ajstractos en función de sujeto. De esta forma fue como coincidió el comportamiento gramatical de estos sustantivos (abstractos) con la expectativa que los hablantes poseen de la función sujeto.

Este otro valor que le otorga Company al artículo en esta época coincide también con la función que actualmente los gramáticos le atribuyen al artículo determinado en español. Así, Lapesa ${ }^{20}$ delimita el valor del artículo tomando cono base la idea de determinación. Para él, el valor del artículo sería el de su cárácter actualizador, un actualizador sin sustancia semántica frente a los demostrativos

Sir lugar a dudas, para Company, las características de estos sujetos genéricos sin artículo, aunadas a la indeterminación categorial de sustantivos como cristianos, moros, lueron decisivas para provocar la extensión y generalización del artículo en esta función, y extenderse, luego, análogamente, a otro tipo de sustantivos.

Ahora bien, en nuestra opinión, estas dos causas no nos parecen tan determinantes a la hora de provocar la extensión del artículo, o al menos, no estás dos exclusivamente, pues el contexto, ya gramatical inmediato ya histórico- 
situacional, siempre permitiría inferir el empleo funcional (sujeto o predicativo) de estas voces al mismo tiempo que su significado denotativo o referencial.

No estamos diciendo con ello que estas causas no sean válidas, sino que desde un punto de vista sociolingüístico resultan incompletas e insuficientes para la explicación de la extensión del artículo en castellano medieval. Esta explicación se atiene únicamente a factores internos, lingüísticos, por ello, resultaría válida dentro de una Gramática Histórica bidimensional (tiempo y espacio), pero en el marco de una Historia Sociolinguística de la Lengua debemos tener en cuenta a los hablantes, sus actitudes, sus inquietudes, su ideología, ampliándola así a una perspectiva tridimensional (tiempo, espacio y hablante).

A nuestro entender, esos dos factores lingüísticos intervendrían en la extensión del artículo, pero no únicamente ellos solos, sino que también debieron intervenir otros factores, externos, sociales, ideológicos; estos elementos sociales pueden ser, en nuestra opinión un espíritu materialista y pragmático propio de la burguesía, el sustancialismo y organicismo tomista de origen aristotélicos y una potenciación o enfatización de los elementos idiosincráticos del romance como enfrentamiento al latín que monopolizaba el ámbito de la cultura. Pues bien, todos estos aspectos sociales o ideológicos son los que vamos a intentar comentar a continuación.

1) Carácter pragmático de la burguesía: Tras la desaparición de la mortandad creada por «la peste negra» debido a un fenómeno de carácter biológico se va a producir el movimiento transmigratorio contrario a la ruralización: la urbanización, la población abandona el campo en favor de la ciudad. ${ }^{21}$ Las ciudades renacen desde las propias «cenizas» de las viejas ciudades romanas, pero junto a ellas aparecen más viviendas y barrios enteros fuera de las murallas antiguas: sor los burgos: y de aquí vendrá el nombre de burgueses de sus habitantes ${ }^{22}$.

Mauro Olmeda ${ }^{23}$ señala que nos hallamos ante un nuevo tipo de aglomeración humana tanto por la relación entre la población que la integra como por la composición social de las mismas. Desde un punto de vista económico, la ciudad se define a partir de relaciones de carácter mayoritariamente comercial, el centro urbano se convierte en el centro comercial por excelenciá. La vinculación entre comercio y ciudad llega a ser tal que incluso Mauro Olmeda considera «que no puede dudarse de que el origen de estas ciudades está directamente

21 V. Boix Reig, Urbanismo y derecho, Editorial Tri: :ium, Madrid, 1990, pág 27.

22 M. A. García Ochoa, Esquemas mentales del hombre medieval, Universidad de Puerio Rico, Puerto Rico, 1988, pág. 110.

23 Mauro Olmeda, El desarrollo de la sociedad, Tomo IV, Editorial Ayuso, Madrid, 1977, pág 195.

24 Ibid. pág. 228. 
relacionado con el nacimiento del comercio». ${ }^{24}$ Así, la burguesía va a condicionar el marco esencial de la nueva ciudad.

La aparición de la burguesía supuso el surgimiento de una concepción de carácter pragmático y materialista. Esta ideología práctica posiblemente tendrá su correspondiente reflejo en el desarrollo lingüístico. Entre las diferentes posibilidades de dicho reflejo, nos planteamos ahora el observar cómo lo material adquiere, tanto en el interior de la propia ideología como en el ámbito lingüístico, una importancia decisiva, derivándose de ello una focalización linguística de la relevancia que lo concreto consigue entre la nueva clase social. La burguesía practica una visión del mundo en la cual lo realista, «la cosa» se define en términos de esenciabilidad, de sustanciabilidad (en intima relación con la filosofía tomista, como veremos posteriormente en el punto 2).

Queremos señalar, por tanto, que el aspecto ideológico e idiosincrático de la clase burguesa va a verse reflejado en determinados elementos constitutivos de la lengua. Entre cllos podemos vislumbrar una ampliación del fenómeno de la sustantivación con respecto al que se daba en épocas anteriores, justificado por el mencionado deseo de concreción, de objetualización. Junto a él hallamos un mayor índice en el uso de actualizadores (demostrativos, deícticos...) y, entre otros, un desarrollo de las formas perifrásticas, por cuanto los circunloquios, independientemente de la economía del lenguaje, contribuyen a una mayor aproximación explicativa del referente extralingüístico o del proceso designado.

En definitiva, el proceso de aprehensión objetual no se manifiesta meramente en el ámbito cognitivo, sino que dicha cognición abarca, entre otros ámbitos, el propiamente lingüístico.

2) El sustancialismo y organicismo tomista: Es importante observar qué pasa en la filosofía para conocer lo que sucede en la lengua. Ha tenido que ocurrir al go en la filosofía que deteremine el cambio lingüístico en la Edad Media. Sin duda, en esta época el momento álgido de la filosofía lo ocupará el tomismo. Éste representa el corporativismo, el sustancialismo, el organicismo, el materialismo. Santo Tomás, siguiendo la visión inmanentista de Aristóteles, considerará que la sustancia es el «ser» propiamente dicho, por ello, es ante todo cosa, algo separado, independiente, que existe por sí y no en otro. Para Santo Tomás la sustancia es únicamente el individuo concreto ${ }^{25}$.

Santo Tomás coincide con Aristoteles en pensar que, efectivamente, el objeto propio y proporcionado del conocimiento es la forma o esencia de las cosas materiales, la cual consigue nuestro entendimiento a través de un proceso de abstracción a partir de las imágenes sensibles de los objetos ${ }^{26}$.

25 F. Canals Vidal, Historia de la Filosofía medieval.Curso de filosofía tomista, Editorial Herder, Barcelona, 1980, pág, 166.

26 B. López Molina, El hombre, imagen de Dios. Introducción al pensamiento medieval de Tomás de Aquino, Universidad de Granada, Granada, 1987, pág 69. 
Considera que las cosas están compuestas de sustancia y accidentes, y que las sustancias, en un plano más profundo, son compuestos de materia y forma. La materia es concebida como aquello de lo que proviene un ser y le es inmmanente, aquello de lo que está hecha una cosa; la forma sería la esencia. En realidad, sigue Santo Tomás dando importancia a la forma pero ésta la acerca más a la realidad empírica y material que San Agustín. En esta época se le otorga una mayor relevancia a lo material, acercándolo un poco más al estatus que poseía lo espiritual, es decir, el tomismo eleva, dentro de la sustancia, la materia a un mismo nivel que la forma, otorgando así a la forma un estatus que hasta entonces no le había ofrecido el marcado idealismo de San Agustín.

Es precisamente este énfasis orientado hacia la materia el que provocará un sentimiento fuertemente pragmático y una concepción más materialista que en la época anterior. Creemos que la intensificación de este factor filosófico potenciaría en la colectividad una ideología donde lo organicista, lo material y lo concreto ocuparía un lugar relevante. Esta focalización hacia lo inmanente se refleja en la literatura en lo más empírico, el tema de «la sangre», mientras que en la lengua se puede observar en la extensión del uso del artículo y los deícticos, pues éstos, además de actualizar y concretar los sustantivos, amplían el número de formas que aparecen en la secuencia. Habría que recordar que en las lenguas romances frente al sintetismo triunfó el analismo, porque de esta manera había más formas (linguiísticas); de este modo, se potenció una amplitud formal, porque quizás las formas lingüísticas sean lo más cercano en la lengua al organicismo en la filosofía tomista.

Dentro de este marco, se explicaría el hecho de que en esta época aparecieran estructuras nominales con doble determinante que han desaparecido en el español moderno. Un ejemplo podría ser el de la estructura de ARTíCULO + POSESIVO (Que digas el tu nombre al rey) que actualmente nos puede llamar la atención por su redundancia actualizadora, pero que se puede comprender mejor dentro de esta potenciación de la ampliación formal (triunfo del analismo).

3) Potenciación de los elementos idiosincráticos del romance:

Debemos recordar que el artículo, además de implicar la concreción del objeto linguiístico acorde con la ideología materialista de la burguesía y con la visión organicista del tomismo, supone un deseo evidente de diferenciación de la lengua romance frente al latín, que hasta entonces había constituido la lengua de cultura, y al unísono una consecuente reivindicación del estatus lingüístico igualitario de esta lengua romance respecto de la latina, dentro de ese ámbito culturalista monopolizado por el latín.

No debemos perder de vista que, como afirma Gimeno ${ }^{27}$, durante la Alta

${ }_{27}$ F., Gimeno Menéndez, «Aproximación sociolingüística de los orígenes del español»,Actas del I Congreso Internacional de Historia de la Lengua Española, Arco-Libros, Cáceres, 1988, págs. 1183-1192. 
Edad Media el contex to sociolingùístico correspondía a una situación general de «diglosia», de tal modo que una variedad lingüística es utilizada como variedad estándar y la otra u otras como vernáculos. El estándar sería el latín medieval, usado como variedad escrita y hablada formal, y el romance una variedad hablada familiar e informal. Así, en determinados círculos (enseñanza, vida política y administrativa, monasterios e iglesia) el latín medieval seguiría desempeñando las funciones de una lengua estándar (unificadora, separadora, de prestigio y de marco de referencia). Además, considera que el romance castellano no surgió como un proceso de «criollización», sino como propio desarrollo de la dinámica diferenciadora del vernáculo.

Por lo tanto, siguiendo la mencionada «dinámica diferenciadora» del romance, si el castellano desea oponerse al latín como lengua de cultura, necesita recurrir a los elementos que le son propios, característicos e idiosincráticos, y lógicamente uno de ellos es la creación del artículo ${ }^{28}$, creado por la corriente popular de las lenguas románicas. E1 latín clásico carecía de artículo y, en consecuencia, el elemento lingüístico podría considerarse más ideal, general y abstracto, frente a la concreción de dichas unidades en esta época.

Ahora bien, no queremos decir con esto que el latín considerara la realidad de forma abstracta, lo que sucede es que hasta entonces el aspecto materialista no había supuesto un estado de pertinencia tan elevado como el que corresponde a la época analizada. Existían deícticos, por supuesto, pero no un deseo extremo de focalización en lo concreto. Se trata de una época en la que se experimentó un enfoque diametralmente opuesto al anterior.

El artículo es una creación romance, ya que en latín no existía. Pero hay diferentes interpretaciones de cómo se formó el artículo. Pidal ${ }^{29}$ piensa que el artículo se originó por el debilitamiento significativo que sufrieron algunos demostrativos. Amado Alonso ${ }^{30}$ piensa que la aparición del artículo está intimamnete unida a la pérdida de la flexión nominal. Así pues, este autor no entiende el artículo desde el demostrativo, sino desde lo nominal. En latín la significación del sustantivo estaba fundida con la función sintáctica. sin embargo, en romance se puede expresar el significado del sustantivo en sí, independientemente de su significado en la sintaxis. Las relaciones sintácticas las expresan elementos adjuntos. El artículo viene a separar en el sustantivo los valores formales y funcionales (sintácticos) de su significado y a destacar el

28 V. Väanänen, introducción al latín vulgar, Gredos, Madrid, 1968, págs. 213-214.

29 R. Menéndez Pidal, Manual de Gramática histórica de la Lengua Española, Espasa-Calpe, Madrid, $19^{\mathrm{a}}$ ed., 1987.

30 A. Alonso, «Estilística y gramática del artículo en español», Estudios lingüísticos. Temas españoles, $3^{\mathrm{a}}$ ed., Madrid, 1967, págs.125-160.

31 Op. cit, págs. 23-44. 
significado independiente del sustantivo. Y finalmente, Lapesa ${ }^{31}$ no entiende el artículo desde el desgaste significativo de algunos demostrativos, sino desde nuevas funciones de las antiguas formas. Tan significativo como el aumento de frecuencia es el incremento del adnominal de los demostrativos. Así la presencia o ausencia de ille o ipse junto al sustantivo fue progresivamente marcando la distinción entre realidades actuales y conceptos virtuales; sólo desde entonces existió propiamente artículo.

Esta oposición, que hemos comentado, que mantiene el castellano frente al latín para arrebatarle el ámbito de cultura se enmarcaría dentro de una concepción cíclica de la historia. Los ciclos son una serie de procesos típicos que se repiten constantemente a lo largo de la historia de la lengua. Todos estos procesos constan siempre de tres etapas: 1) periodo de crisis, en el que hay una desorientación y una búsqueda de soluciones ante el conflicto que se produce por un choque con la realidad; 2) periodo de esplendor, porque se produce una unificación entre lengua y realidad, y 3) periodo de transición, hasta llegar a una nueva crisis. Pues bien, a cada uno de estos periodos de crisis, exaltación y transición le llamamos ciclo. Dividimos la historia de la lengua en ciclos porque consideramos que cada momento de esta es generado por el anterior y regenerador del siguiente. Por lo tanto, en nuestra historia de la lengua no hay rupturas, ni discontinuidades, sino que es una historia lineal pero dialéctica. Nos encontramos, así, ante un ciclo que se caracteriza por la oposición (ya dentro del romance, del castellano oral frente al castellano como lengua de cultura o lengua literaria.

De este modo, queremos destacar que factores de índole social (proceso de urbanización) o económica (concepción materialista de la burguesía), factores filosóficos (el organicismo tomista de origen aristotélico) y factores de índole «dialéctica» (el enfrentamiento que mantiene el castellano con el latín para convertirse en una lengua de cultura), provocan, en definitiva que la ideología de esta colectividad se defina en unos términos en los que lo material adquiera una importancia tan extrema que tenga su reflejo lingüístico, que hasta entonces no había sido motivado. Este reflejo lingüístico se manifiesta en la extensión del uso del artículo que tiene lugar en el siglo XIII. Con ello no queremos decir que sólo influyeran estos factores sociales e ideológicos comentados anteriormente, probablemente se nos escapen otros factores que no hemos tenido en cuenta. Únicamente queríamos proponer que, además de los dos factores lingüísticos que propone Company, el de la indeterminación de categoría léxica que se evita mediante la sustantivización del adjetivo por parte del artículo y el de la actualización de los sustantivos abstractos por el carácter actualizador del artículo, nos son insuficientes para dar una explicación sociolingüística de la extensión del artículo en el español del siglo XIII. 